\title{
Relative Effects of Varying Light Conditions on the Growth of Toxic and Non-Toxic Strains of Microcystis aeruginosa
}

\author{
Gbenga Folorunsho Oginni ${ }^{*}$, Lord Setsoafia Dzakpasu², Wilson Anand Babu ${ }^{3}$, \\ Ayo Oisagah Ezekiel ${ }^{4}$
}

${ }^{1}$ Laboratory of Environmental and Life Sciences, University of Nova Gorica, Nova Gorica, Slovenia

${ }^{2}$ Hvivo Research Centre, Imperial College London, London, UK

${ }^{3}$ Department of Medicine, University of Verona, Verona, Italy

${ }^{4}$ Department of Biological Sciences, Joseph Ayo Babalola University, Ilesa, Nigeria

Email: *Gbenga.oginni@yahoo.com

How to cite this paper: Oginni, G.F., Dzakpasu, L.S., Babu, W.A. and Ezekiel, A.O. (2021) Relative Effects of Varying Light Conditions on the Growth of Toxic and Non-Toxic Strains of Microcystis aeruginosa. Journal of Environmental Protection, 12, 1161-1173.

https://doi.org/10.4236/jep.2021.1212068

Received: May 25, 2021

Accepted: December 14, 2021

Published: December 17, 2021

Copyright $\odot 2021$ by author(s) and Scientific Research Publishing Inc. This work is licensed under the Creative Commons Attribution International License (CC BY 4.0)

http://creativecommons.org/licenses/by/4.0/

\section{(c) (i) Open Access}

\begin{abstract}
Harmful algae bloom constitutes a major problem facing water bodies particularly fresh and marine water system. Microcystis aeruginosa represents a major causative organism found in the water. Light plays a major role in the growth and variation of $M$. aeruginosa in water. What is still inadequate, is the data on the effects of different light conditions on the growth of Microcystis aeruginosa. In this study, two strains of Microcystis aeruginosa PCC 7806 (toxic strain) and PCC 7005 (non-toxic strain) were exposed to varying light intensities at $0,30,60,120,300,350 \mu \mathrm{Mol}$ photon $\mathrm{m}^{-2} \cdot \mathrm{S}^{-1}$ to measure their growth and pigmentation. This study observed similarities in growth and pigmentation between toxic strain (PCC 7806) and non-toxic (PCC 7005) strain. Also, at short exposure to light, Toxic strain was seen to be better tolerant of light than non-toxic strain, with non-toxic strain showing better ability to recover from light stress after twenty days of culture. These findings suggest that Toxic strain (PCC 7806) and Non-toxic strain (PCC 7005) of $M$. aeruginosa respond similarly with respect to growth but differ in their light retention capacity over time and this could be useful in predicting the possible conditions of algal bloom.
\end{abstract}

\section{Keywords}

Cyanobacteria, Light Intensity, Optical Density, Pigmentation, Photons

\section{Introduction}

Harmful algal bloom (HABs) represents a major problem across the world, par- 
ticularly more pronounce in lakes and reservoirs, influencing municipal, agricultural and industrial water sources. Cyanobacteria is known to be the primary organism causing algal bloom. These contaminated water bodies contain hepatotoxins which are health hazards to humans and animals [1]. Cyanobacteria are phytoplankton species that occur in fresh and brackish water systems across the world [2] [3]. Studies into the dynamics of cyanobacterial blooms predict that the expected increase in global temperature will result in increased surface water temperatures and thermal stratification as well as change meteorological patterns possibly stimulating increased cyanobacterial growth rates [4] and higher frequency of bloom events.

Species of cyanobacteria differ in their morphology and may exist as single cells or filaments [5]. Cyanobacteria generally dominate in reservoirs containing high nutrient loads and stagnant water although cyanobacterial blooms do occasionally occur in oligotrophic systems and are favored by water temperatures between $15^{\circ} \mathrm{C}$ and $30^{\circ} \mathrm{C}$ [6] [7]. Report indicate that Cyanobacteria blooms are more predominant and with higher intensity in fresh and coastal ecosystem [8]. Microcystis aeruginosa represent a major toxin-producer of cyanobacteria and can produce different hepatotoxin, the most significant being microcystin-LR. Report indicated that prolong exposure to low levels of microcystin could trigger liver tumor [9]. Hepatotoxins are secondary metabolites offering some physiological advantage to toxic strain of $M$ aeruginosa. Increase in hepatotoxin production is influenced by high temperature and light intensity [10]. A major determining factor for global algae bloom toxicity is the variation between toxic and Non-toxic strains, so there is a need to critically evaluate the factors that increase or decrease the growth of these strains [6]. Algal competition may be determined by variation between biotic and abiotic factors. Studies have shown that light constitute an important factor in species selection of algae and cyanobacteria [11] [12]. Another Laboratory study also validates that two non-toxic strains of $M$. aeruginosa show higher competitive advantage than two toxic strains under low light condition, even when the toxic strains was seen to initially dominant over the Non-toxic strain [13]. In this situation, low light intensity constitutes the primary factor of the competitive outcome. One activity that occurs during the occurrence of algal bloom is that light intensity and penetration in the water column is reduced. As a result, there is an increase in cell concentration and therefore reduction in the rate of photosynthesis in very deep-water layers [14]. To control such challenge, Microcystis cells effectively utilise their gas vacuoles in rising to cell surface even though this method is a benefit for nutrient and light competition, it is still not yet completely manageable and, could not be seen as entirely reliable [15]. Apart from chlorophyll content that was determined in this study, M. aeruginosa have other pigments-phycobiliproteinswhich absorbs at varying wavelengths and is involved in energy transmission to chlorophyll. Phycobiliproteins could make up to $60 \%$ of the soluble protein content in cyanobacteria [16] and permit them to survive even in extreme conditions of reduced light concentration even across in polar regions [17]. These 
pigments can be categorized into phycocyanin (PC), allophycocyanin (APC) and phycoerythrin (PE). PC show a color between purple to dark cobalt blue with a peak absorption ranging between $610-620 \mathrm{~nm}$; while APC is bright greenish or aqua-blue with the highest absorption ranging between $650-655 \mathrm{~nm}$ and PE shows bright pink with a peak absorption ranging between $540-570 \mathrm{~nm}$. The most notably expressed phycobiliproteins in cyanobacteria are allophycocyanin and phycocyanin while phycoerythrin is present in a minute amount and not present in all types of cyanobacteria [18]. The continuous dominance of $M$. aeruginosa is generally ascribed to high temperatures, elevated nutrient concentrations, and reduced turbulence [19]. Studies performed in a hypereutrophic lake show that the intensity of light in the water column could be the greatest determining factor regulating the growth and variation of $M$. aeruginosa. In another study, it was revealed that, $M$. aeruginosa species has the capacity to survive high light intensity and then regarded to be more tolerant at higher light concentrations [20]. Although high-light intensities could be harmful to cyanobacteria species, the responses and relationships of their relative growth, pigmentation, and cell concentration still need to be appropriately look into. Therefore, the main aim of this study was to determine the effect of light intensities on the growth of toxic (PCC 7806) and non-toxic strain (PCC 7005) of M. aeruginosa and to evaluate the pigment contents associated with growth.

\section{Materials and Methods}

\subsection{Cyanobacterial Culture Growth}

Axenic culture of Microcystis aeruginosa non-toxic (PCC 7005) and toxic (PCC 7806) strains were obtained from Institute Pasteur (Paris, France). $10 \mathrm{ml}$ of precultures were grown for two weeks at $28^{\circ} \mathrm{C}$ and constant rocking $(150 \mathrm{rpm})$ in 50 $\mathrm{ml}$ flasks until they reached the concentration of $10^{7}$ cells $/ \mathrm{ml}$ and then used to inoculate $50 \mathrm{ml}$ of sterilized Blue Green (BG-11) medium obtained from Sigma-Aldrich United Kingdom. Cultures were grown for 6 - 8 weeks under continuous agitation $(130 \mathrm{rpm})$ and $12 \mathrm{~h}$ light/dark cycles until the concentration reached $2 \times 10^{7}$ cells $/ \mathrm{ml}$. Cultures were irradiated with cool white fluorescent tubes with a photon flux density of $30 \mu \mathrm{mol} \cdot \mathrm{m}^{-2} \cdot \mathrm{sec}^{-1}$. Subcultures were prepared by aseptically inoculating $50 \mathrm{ml}$ of fresh BG-11 medium with $5 \mathrm{ml}$ of $M$. aeruginosa from 6 - 8 weeks culture above [21].

\subsection{Growth Experimental Setup}

Experiment was conducted in an incubator containing shaker (Vibromix 313 EVT, Tehtnica, Slovenia) and was maintained at constant temperature of $28^{\circ} \mathrm{C}$ throughout the experimental period. In this experiment, $M$. aeruginosa at varying light conditions (toxic strain PCC 7806) and (non-toxic strain 7005) cells were subjected to six photon flux levels $(0,30,60,120,300$, and $350 \mu \mathrm{Mol}$ photon $\left.\mathrm{m}^{-2} \cdot \mathrm{S}^{-1}\right)$ simultaneously. The cultures were subjected to continuous agitation $(130 \mathrm{rpm})$ which ensure adequate mixture at $12 \mathrm{~h}$ light/ dark cycle. At exponential stage of growth, the cells were used in the estimation of the growth rate, 
pigmentation, Cell concentration. At zero $\mu \mathrm{Mol}$ photon $\mathrm{m}^{-2} \cdot \mathrm{S}^{-1}$ light intensity, it means that light was completely prevented from the culture medium. The experiment was done thrice to validate reproducibility of data with replicates being produced twice.

\subsection{Growth Determination at $\mathrm{OD}_{730}$}

To estimate the growth of cyanobacteria, the OD730 (optical density at $730 \mathrm{~nm}$ ) was measured by taking $1 \mathrm{~mL}$ of sample from each $250 \mathrm{~mL}$ flask containing the experimental culture. The OD730 was measured with UV-Vis spectrophotometer (UV/Vis spectrophotometer Lambda $650 \mathrm{~S}$, United Kingdom) at an optical absorption wavelength of $730 \mathrm{~nm}$ [22].

\subsection{Determination of Pigment Contents}

Chlorophyll a, was examined at the mid-exponential stage of growth under varying light intensities with temperature remaining constant at $28^{\circ} \mathrm{C}$ measurements were taken by harvesting cells through centrifugation at $10,000 \times \mathrm{g}$ for 10 minutes at $4^{\circ} \mathrm{C}$, followed by resuspending in $90 \%$ methanol and kept in the dark at $4^{\circ} \mathrm{C}$ overnight. The resulting suspension was centrifuged again and the supernatant was used to measure the absorbance at $660 \mathrm{~nm}$ using a UV/Vis spectrophotometer Lambda $650 \mathrm{~S}$. Carotenoid concentrations were estimated using the same extract but with absorbance measured at $480 \mathrm{~nm}$. For estimation of phycocyanin (PC), allophycocyanin (APC) and phycoerythrin (PE), cells were centrifuged at $3400 \times \mathrm{g}$ for 15 minutes, resuspended in $0.05 \mathrm{M}$ phosphate buffer $(\mathrm{pH}$ 6.7) then ruptured using a probe sonicator (SARTORIUS labonic M). The extract was centrifuged at $3400 \times \mathrm{g}$ for 15 minutes at $4^{\circ} \mathrm{C}$ and the supernatant used to measure the absorbance at, 620 and 640 and $655 \mathrm{~nm}$ [23]. These wavelengths are the most suitable wavelengths for expression of the pigments because peak absorption is within these ranges.

\subsection{Evaluation of Cell Concentration}

M. aeruginosa number (PCC 7806 and PCC 7005) were estimated by counting with Neubauer hematocytometer under Olympus IX81 inverted epifluorescence microscope equipped with a $300 \mathrm{~W}$ Xenon lamp at 40× magnification. To determine Microcystis aeruginosa cell concentration, $10 \mu \mathrm{l}$ of $M$ aeruginosa culture were loaded in a Levy Hemocytometer (Hausser Scientific 100 MM deep, USA) cell counting chamber. Cells in major quadrants were counted under the microscope and the cell numbers from 4 major quadrants was averaged. The cell number per ml was calculated applying the formula:

cell concentration $/ \mathrm{ml}=$ average cell number $\times 10000 \times$ dilution factor

\subsection{Dark Reaction}

For the dark reaction, $M$. aeruginosa cells was devoid from light source under same experimental period of time with other light conditions. This was done for 
both toxic and Non-toxic strain. All experimental parameters were measured including growth rate, Cell concentration, Chlorophylla, Carotenoid, Phycocyanin, Phycoerythrin and Allophycocyanin.

\section{Statistical Analysis}

One-way analysis of variance (ANOVA) determinations were performed to determine the outcome of light intensity on the growth of $M$. aeruginosa in water under a different light intensities. The Statistical Analysis One way ANOVA was the appropriate and most suitable test for this study. In this study, light is the only independent variable been measured and varied at various intensities. Hence, the application of one-way ANOVA, two way ANOVA will be unsuitable because we are not analyzing any other variable alongside light intensity [24]. The popular and conventional cut-off for the " $P$ " value to be deemed statistically significant is $5 \%(0.05)$. What a $P<0.05$ suggests is that the possibility of the results in a research being due to chance is $<5 \%$ [25].

\section{Results}

\subsection{Growth of M. aeruginosa at Different Light Intensities}

The growth rate of both strains was strongly affected by varying light conditions. It was observed that both strains of $M$. aeruginosa shows similarities in growth. Higher growth rate was observed at higher light intensities within day two and day four for the toxic strain while non-toxic strain shows highest growth at the highest light intensity on day 2, as evident from Figure 1 and Figure 2 . The toxic strain shows maximum growth at 300 and $350 \mu \mathrm{Mol}$ photon $\mathrm{m}^{-2} \cdot \mathrm{S}^{-1}$ between 2 to 4 days while non-toxic strain shows peak growth at 30,60 and $350 \mu \mathrm{Mol}$ photon $\mathrm{m}^{-2} \cdot \mathrm{S}^{-1}$ between 2 to 6 days.

\subsection{Pigment Analysis}

Pigment analysis indicates a higher cellular concentration of chlorophyll a in

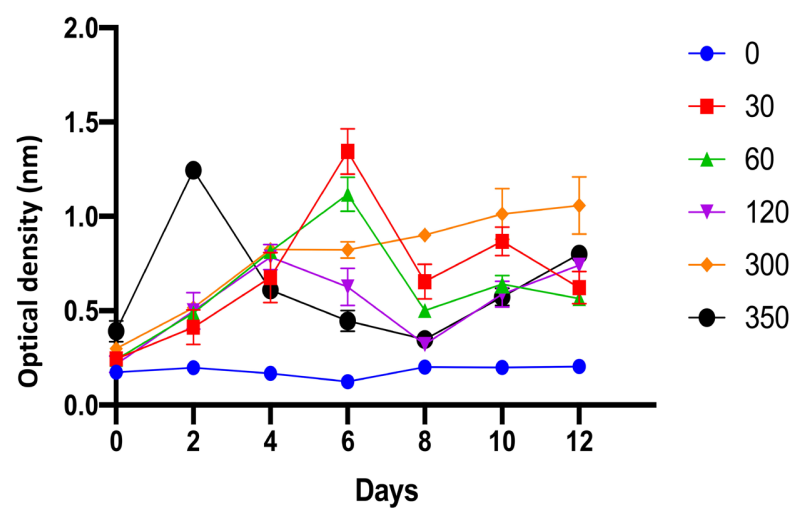

Figure 1. Effects of Light intensity on growth rate of Microcystis aeruginosa Non-toxic strain (PCC 7005) at $\mathrm{OD}_{730}$ after twelve days of culture. 


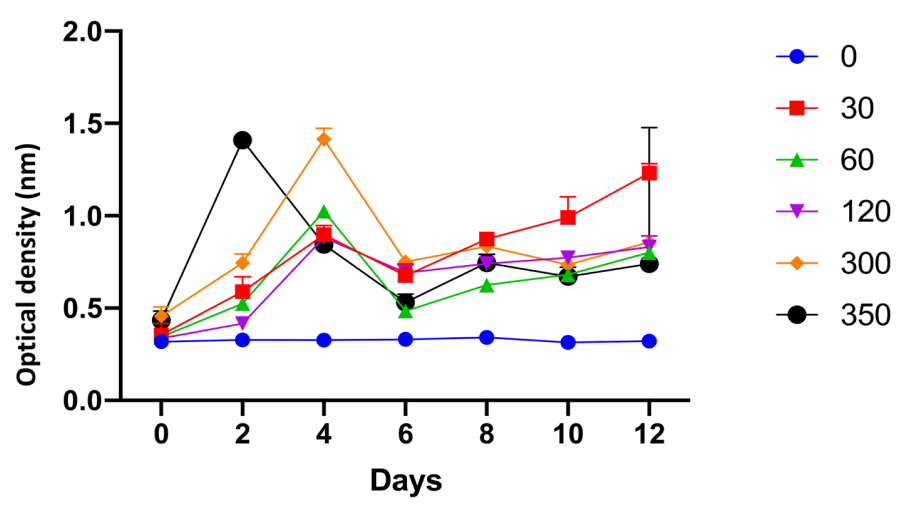

Figure 2. Effects of Light intensity on growth rate of Microcystis aeruginosa toxic strain (PCC 7806) at $\mathrm{OD}_{730}$ after twelve days of culture.

Non-toxic strain (PCC 7005) than toxic strain (PCC 7806) with the highest chlorophyll a concentration noticed at $300 \mu \mathrm{Mol}$ photon $\mathrm{m}^{-2} \cdot \mathrm{S}^{-1}$ for Non-toxic strain and $120 \mu \mathrm{mol}$ for toxic strain respectively. while the carotenoid level (t-test, $p<$ $0.05)$ [One-way ANOVA: $\mathrm{F}_{(1,10)}=4.965, p=0.3562$ ] of both strains was within same range. PCC 7005 showed significant differences in chlorophyll concentration this was 1 time higher, than toxic strain (PCC 7806). This evidence is supported by the statistical analysis that not all the mean of light intensities is equal. There is a difference between the means for PCC 7005, the observed F one-way ANOVA statistic [ANOVA: $\left.\left.\mathrm{F}_{(5,36)}=2.477, p=0.0035\right)\right]$. Whereas, in PCC 7806 the one-way ANOVA statistics [ANOVA: $\mathrm{F}_{(5,36)}=2.4477, p=0.0055$ ] and the $\mathrm{p}$ value obtained was $0.0035<0.05$. It can be said that, there is not enough evidence to claim that all 6 light intensity reading are equal at significance level 0.05. Therefore, light concentration is significant and has effect on the non-toxic strain than toxic strain.

In the case of Phycocyanin at $620 \mathrm{~nm}$, similarities occur in their cellular content for toxic and non-toxic strain except for the high cellular content observed at $300 \mu \mathrm{Mol}$ photon $\mathrm{m}^{-2} \cdot \mathrm{S}^{-1}$ in non-toxic strain in the graph Figure 4 with (t-test, $p<0.05)$. The one-way ANOVA reinforces no significant differences exist between PCC 7005 and PCC 7806 for Phycocyanin at $620 \mathrm{~nm},\left[F_{(1,10)}=4.965\right.$, $p=0.8041]$. There are no significant differences between the means of PCC 7005 and PCC 7806 for Phycocyanin at $620 \mathrm{~nm}$.

Phycoerythrin at $655 \mathrm{~nm}$ also show a similar cellular content for toxic and non-toxic strain. For Allophycocyanin, toxic strain shows higher cellular concentration than non-toxic strain recording it peak concentration at zero light intensity level as seen in Figure 4 below. For phycocyanin at $640 \mathrm{~nm}$, a similar cellular content was noticed for the toxic and non-toxic strain with an exception at $350 \mu \mathrm{Mol}$ photon $\mathrm{m}^{-2} \cdot \mathrm{S}^{-1}$ with toxic strain showing high cellular content.

(t-test, $p<0.05)$ [ANOVA: $\mathrm{F}_{(1,10)}=4.965, \mathrm{p}=0.4341$ ]. The $p$-value is $p=$ 0.4341 , and since $p=0.4341 p=0.4341>0.05$. There is no significant difference between PCC 7005 and PCC 7806 for Phycoerythrin. Allophycocyanin on the other hand has (t-test, $p<0.05$ ) [ANOVA: $\mathrm{F}_{(1,10)}=2.4477, p=0.1173$ ]. Using the 
$\mathrm{P}$-value approach, since $p=0.1173 ; p=0.1173 \geq 0.05$. There is no significant difference between PCC 7005 and PCC 7806 for Allophycocyanin. The t-test is a method that helps in determining whether there is a statistical difference between two populations, however, ANOVA helps in determining whether three or more groups are statistically different from each other. Hence, ANOVA is most suitable measure due to the factors such as chlorophyll, allophycocyanin have been measured at six different light intensities [26].

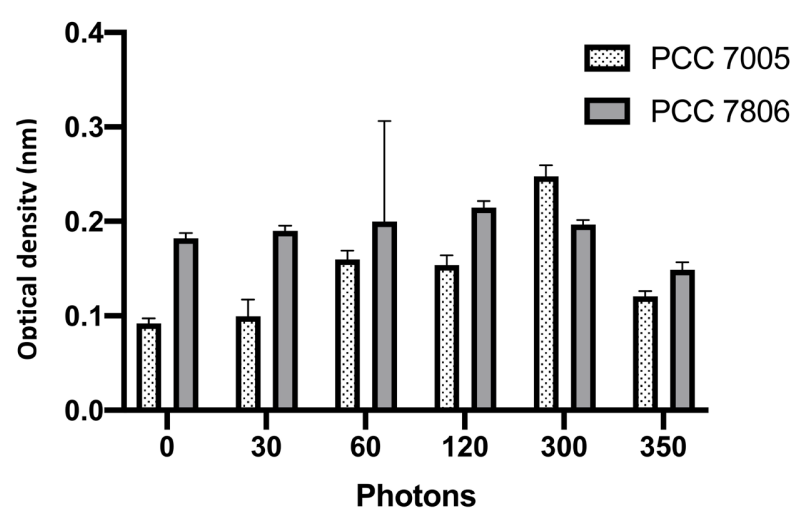

Figure 3. Changes in Chlorophyll a content with respect to culture light intensity at $660 \mathrm{~nm}$ wavelength with the error bars indicating standard deviation.

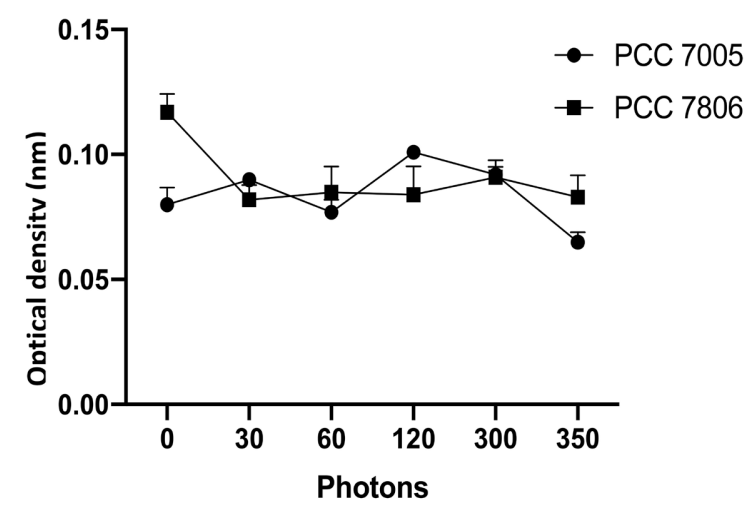

(a)

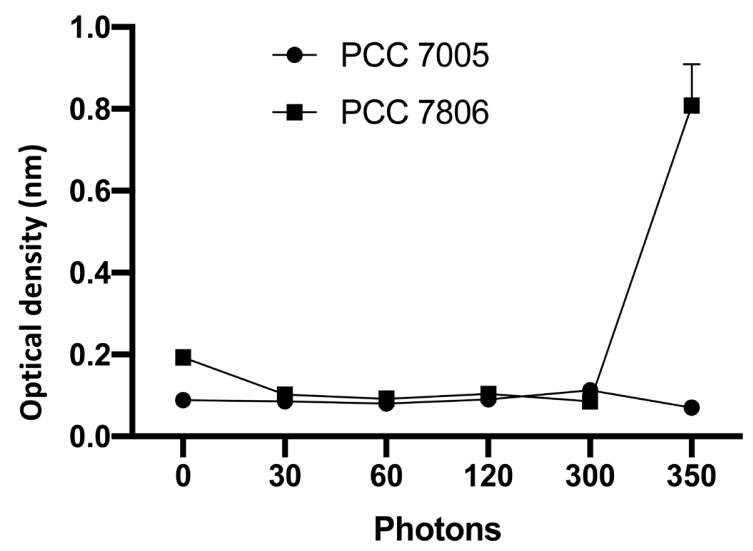

(b) 


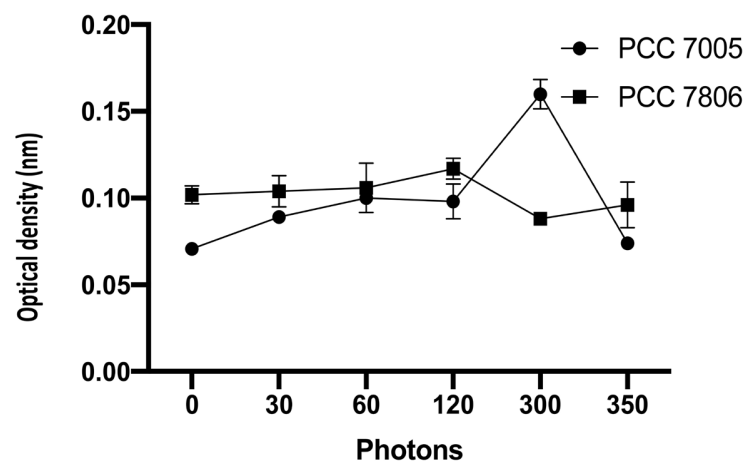

(c)

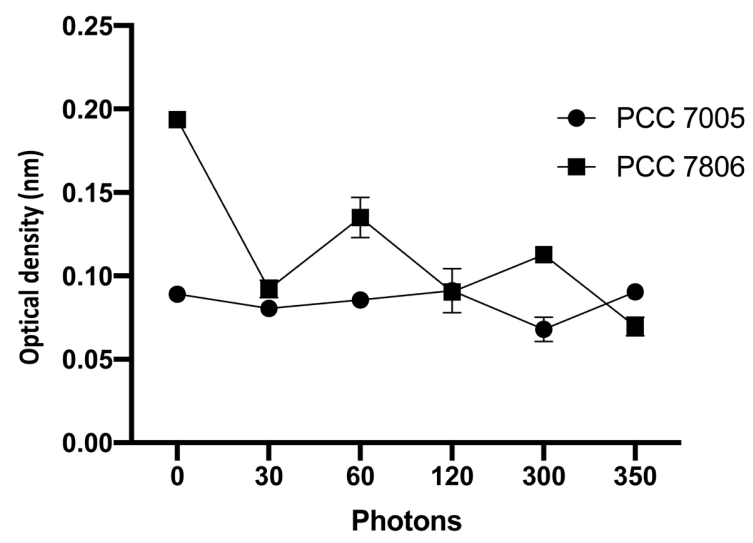

(d)

Figure 4. Cell concentration of (a) Phycoerythrin at $655 \mathrm{~nm}$, (b) Phycocyanin at $640 \mathrm{~nm}$, (c) Phycocyanin at $620 \mathrm{~nm}$, (d) Allophycocyanin at $640 \mathrm{~nm}$ in M.aeruginosa toxic (7806) and nontoxic strain (7005), measured by optical density with respect to varying light conditions.

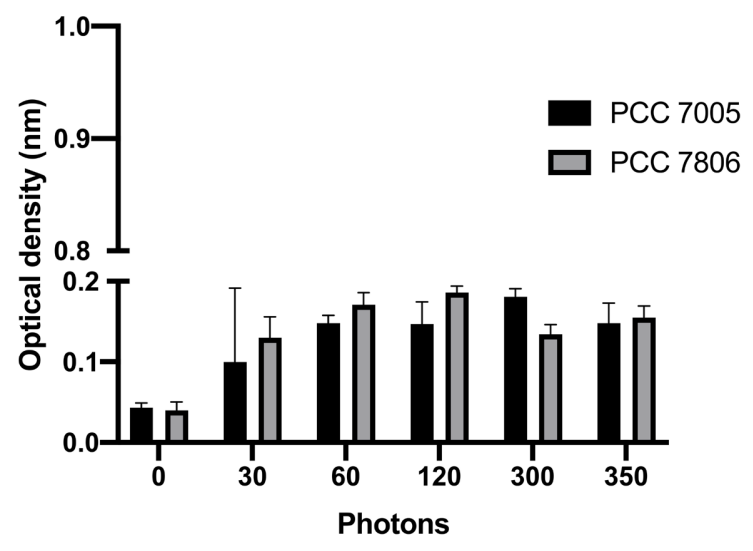

Figure 5. Cell concentration of Carotenoid at $480 \mathrm{~nm}$ for $M$. aeruginosa toxic (7806) and non-toxic strain (7005), measured of optical density with respect to varying light conditions with the error bars indicating standard deviation.

\subsection{Analysis of Cell Concentration}

For cell concentration analysis, cells were analysed at the third, sixth and twenty 
day of culture. At the third day of culture, toxic strain shows higher concentration of cells than Non-toxic strain. The highest concentration of cell was noticed for the toxic strain at $120 \mu \mathrm{Mol}$ photon $\mathrm{m}^{-2} \cdot \mathrm{S}^{-1}$ as seen in (Figure 6(a)). The same trend continues at the sixth day of culture, with the toxic strain still dominating, showing concentration almost as twice of the Non-toxic strain at 120 $\mu \mathrm{Mol}$ photon $\mathrm{m}^{-2} \cdot \mathrm{S}^{-1}$. On the twentieth day, Non-toxic strain gave higher concentration of cell than toxic strain, with the highest cell concentration observed at $300 \mu \mathrm{Mol}$ photon $\mathrm{m}^{-2} \cdot \mathrm{S}^{-1}$.

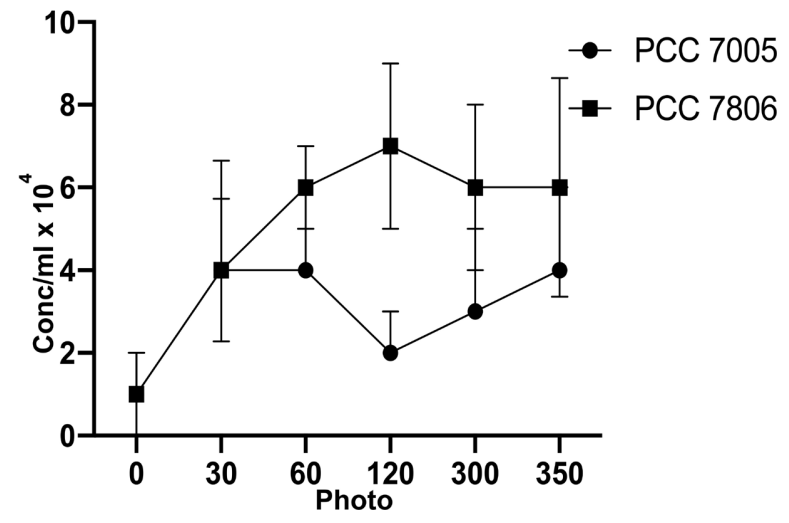

(a)

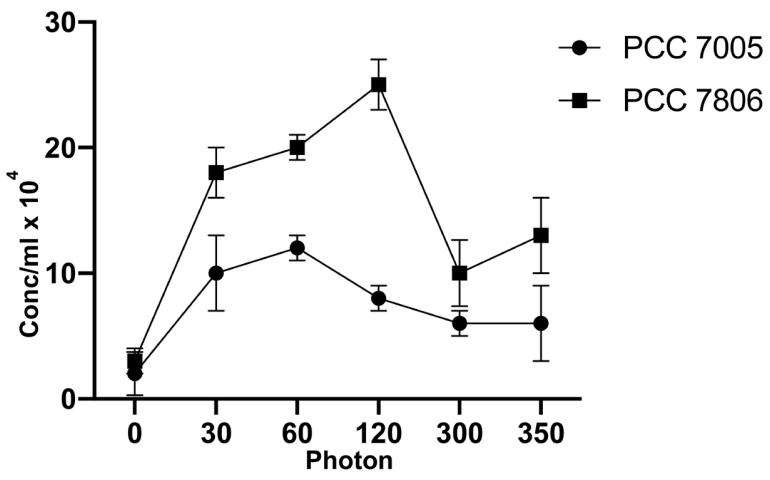

(b)

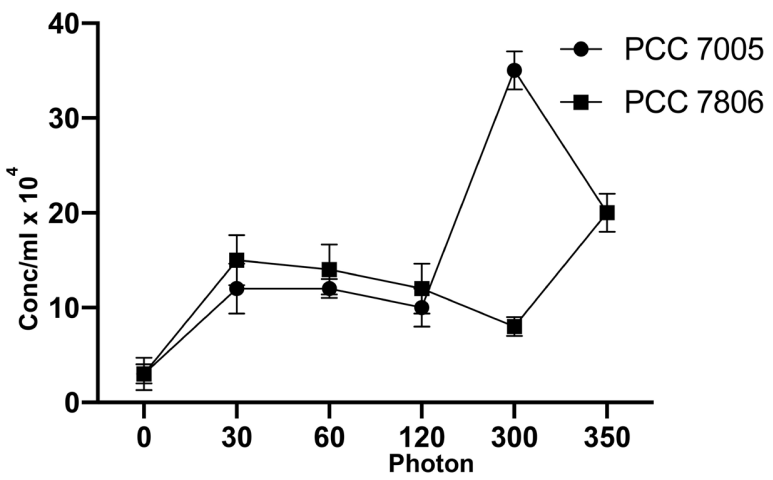

(c)

Figure 6. Analysis of cell concentration at (a) Three days, (b) Six days and (c) Twenty days of culture for $M$. aeruginosa toxic (7806) and non-toxic (7005) strain and exposure to varying light intensity. 


\subsection{Dark Reaction Analysis}

In the case of dark reaction, growth rate was at the lowest with low concentration of cell observed at the third, sixth and twenty day of culture analysis when compared with other light conditions. However, the chlorophyll a content of the toxic strain was observed to be higher than that of the non-toxic strain. Similarly, the carotenoid contents of toxic strain indicate a higher concentration than the non-toxic strain. While, for Phycocyanin and phycoerythrin the toxic strain was observed to be significantly higher in concentration than non-toxic strain. For the Allophycocyanin, the toxic strain was higher in cell content than nontoxic strain as indicated in the Figures 3-6.

\section{Discussion}

The two cyanobacteria strains, toxic strain (PCC 7806) and non-toxic strain (PCC 7005) of M. aeruginosa, responded in a similar manner under different intensities of lights, and with respect to increasing light concentrations, predominantly within light intensity range from 0 to $300 \mu \mathrm{Mol}$ photon $\mathrm{m}^{-2} \cdot \mathrm{S}^{-1}$. Both strains were adversely affected when the light intensity reached $350 \mu \mathrm{Mol}$ photon $\mathrm{m}^{-2} \cdot \mathrm{S}^{-1}$ within the period of sixth days. However, under two days of exposure, neither strain was influenced, even by the extreme light conditions (300 and 350 $\mu \mathrm{Mol}$ photon $\mathrm{m}^{-2} \cdot \mathrm{S}^{-1}$ ), suggesting and indicating that, under a short exposure to increasing-light intensity, both strains would survive. In addition to that, the concentration of cell analysis and, the prolonged exposure (sixth days) increased the stress on both species, toxic strain did show better tolerant capability than non-toxic strains while exposure after twenty days indicates that, the non-toxic recovered considerably from light stress by showing improved growth. Toxic strain has the capacity to endure light stress for shorter durations but lose this tolerance after extended periods of exposure. Light intensities between 30120 , 300 and $350 \mu \mathrm{Mol}$ photon $\mathrm{m}^{-2} \cdot \mathrm{S}^{-1}$ can be considered preferable light conditions for Toxic strain (PCC 7806) while Non-toxic (PCC 7005) range shows optimal growth at 30, 60 and $350 \mu \mathrm{Mol}$ photon $\mathrm{m}^{-2} \cdot \mathrm{S}^{-1}$. In another similar and related studies, as the growth of Microcystis and Anabaena species increased under low light $\left(25 \mu \mathrm{Mol}\right.$ photon $\left.\mathrm{m}^{-2} \cdot \mathrm{S}^{-1}\right)$ but decreased under high light $(200 \mu \mathrm{Mol}$ photon $\mathrm{m}^{-2} \cdot \mathrm{S}^{-1}$ ) [23] [27] [28]). However, this study confirmed that light intensities exceeding $300 \mu \mathrm{Mol}$ photon $\mathrm{m}^{-2} \cdot \mathrm{S}^{-1}$ further intensified stress on both M.aeruginosa strain.

Concerning chlorophyll-a range, the non-toxic strain shows higher concentration than toxic strain at $660 \mathrm{~nm}$, with the highest concentration seen at $300 \mu \mathrm{Mol}$ photon $\mathrm{m}^{-2} \cdot \mathrm{S}^{-1}$ and for toxic strain at $120 \mu \mathrm{Mol}$ photon $\mathrm{m}^{-2} \cdot \mathrm{S}^{-1}$. Carotenoid contents show similarities for both strains of M.aeruginosa with the highest carotenoid contents seen under light intensity $120 \mu \mathrm{Mol}$ photon $\mathrm{m}^{-2} \cdot \mathrm{S}^{-1}$ in toxic strain. In a previous research study, it was shown that the cellular concentration of chlorophyll-a and carotenoids were higher in toxic strain compared to non-toxic strain [23]. For the phycobiliproteins pigments, Phycoerythrin at $655 \mathrm{~nm}$ and 
phycocyanin at $640 \mathrm{~nm}$ shows similarities in concentration for toxic and nontoxic strain except at $350 \mu \mathrm{Mol}$ photon $\mathrm{m}^{-2} \cdot \mathrm{S}^{-1}$ where toxic strain was dominantly higher in growth. At $620 \mathrm{~nm}$ phycocyanin also shows similar trend in growth trajectory for both strain except at $300 \mu \mathrm{Mol}$ photon $\mathrm{m}^{-2} \cdot \mathrm{S}^{-1}$ where non-toxic strain was significantly dominantly higher. For Allophycocyanin at $640 \mathrm{~nm}$, toxic strain was significantly higher across all the light intensity. The differences in the phycobiliproteins pigment concentration are as a result of the variations in efficiency of absorbance at different wavelength.

In the dark reaction, most results gave the lowest range in comparison to the growth at other light intensity levels, with few exceptions. From this study, it could be inferred that, M. aeruginosa cells shows good recovery of photosynthetic activity after protracted exposure to heightened light intensity, with better recovery seen with the non-toxic strain, this simply suggests that, they possess good ability to recover from high light intensity. One possible explanation for the higher resistance of the toxic strains in this experiment could be their lower photosynthetic pigment content and high Carotenoid to Chlorophyll-a ratio. [13]. Similarly, a study reported that the toxic strain of $M$. aeruginosa were less affected by an increment in light exposure for short period of time compared to non-toxic strain [22]. These parameters and factors could simply be valuable in the short and long-time prediction of possible algae bloom behavior pattern.

\section{Conclusion}

The results in this study indicate that growth occurs virtually across all the light intensity levels. This study also confirms that the two strains of $M$. aeruginosa has the capacity to withstand high light intensities as high as $350 \mu \mathrm{Mol}$ photon $\mathrm{m}^{-2} \cdot \mathrm{S}^{-1}$. These results suggest that toxic strain and non-toxic strain of $M$. aeruginosa show similarities in growth and pigmentation. However, differences were seen in the light retention capacity between the two strains with toxic strain having better tolerant of light under short exposure and non-toxic strain with good recovery ability under prolong exposure to light. The information from this study could be used in the monitoring and control of possible bloom situation, particularly with respect to toxic and non-toxic strain of $M$. aeruginosa.

\section{Conflicts of Interest}

The authors declare no conflicts of interest regarding the publication of this paper.

\section{References}

[1] Quan, N.V., Xuan, T.D. and Teschke, R. (2020) Potential Hepatotoxins Found in Herbal Medicinal Products: A Systematic Review. International Journal of Molecular Sciences, 21, Article No. 5011. https://doi.org/10.3390/ijms21145011

[2] Codd, G.A., Lindsay, J., Young, F.M., Morrison, L.F. and Metcalf, J.S. (2005) Harmful Cyanobacteria: From Mass Mortalities to Management Measures. In: Huisman, J., Matthijs, H.C. and Visser, P.M., Eds., Harmful Cyanobacteria, Springer, Dordrecht, 
$1-23$.

[3] Kahru, M., Horstmann, U. and Rud, O. (1994) Satellite Detection of Increased Cyanobacteria Blooms in the Baltic Sea: Natural Fluctuation or Ecosystem Change. AMBIO: A Journal of the Human Environment, 23, 469-472.

[4] El-Shehawy, R. Gorokhova, E., Fernandez, P.F. and Del Campo, F. (2011) Global Warming and Hepatotoxin Production by Cyanobacteria: What Can We Learn from Experiment? Water Research, 46, 1420-1429.

[5] Mur, L.R., Skulberg, O.M. and Utkilen, H. (1999) Chapter 2. Cyanobacteria in the Environment. In: Chorus, I. and Bartram, J., Eds., Toxic Cyanobacteria in Water. $A$ Guide to Their Public Health Consequences, Monitoring and Management, St Edmundsbury Press, London, 15-40.

[6] Callieri, C. (2016) Micro-Players for Macro-Roles: Aquatic Microbes in Deep Lakes. Journal of Limnology, 75, 191-200. https://doi.org/10.4081/jlimnol.2016.1370

[7] Kobos, J., Błaszczyk, A., Hohlfeld, N., Toruńska-Sitarz, A., Krakowiak, A., Hebel, A., Sutryk, K., Grabowska, M., Toporowska, M., Kokociński, M., Messyasz, B., Rybak, A., Napiórkowska-Krzebietke, A., Nawrocka, L., Pełechata, A., Budzyńska, A., Zagajewski, P. and Mazur-Marzec, H. (2013) Cyanobacteria and Cyanotoxins in Polish Freshwater Bodies. Oceanological and Hydrobiological Studies, 42, 358-378. https://doi.org/10.2478/s13545-013-0093-8

[8] Camila, A.T., Miquel, L. and Marcelo, M.M. (2015) Asessement of Effects of Light Availability on Growth and Competition between Strains of Planktothrix agardhii and Microcystis aeruginosa. Microbial Ecology, 71, 802-813.

https://doi.org/10.1007/s00248-015-0719-Z

[9] Humpage, R.A. and Falconer, R.I. (1999) Microcystin-LR and Liver Tumor Promotion: Effects on Cytokinesis, Ploidy, and Apoptosis in Cultured Hepatocytes. Environmental Toxicology, 14, 61-75.

https://doi.org/10.1002/(SICI)1522-7278(199902)14:1\%3C61::AID-TOX10\%3E3.0.C $\underline{\mathrm{O} ; 2-\mathrm{R}}$

[10] ONeil, J.M., Davis, T.W., Burford, M.A. and Gobler, C.J. (2011) The Rise of Harmful Cyanobacteria Blooms: The Potential Roles of Eutrophication and Climate Change. Harmful Algae, 14, 313-334.

[11] Huisman, J., Chorus, I. and Bartram, J. (1999) Toxic Cyanobacteria in Water: A Guide to Their Public Health Consequences, Monitoring and Management. St Edmundsbury Press, London.

[12] Litchman, E., Steiner. D. and Bossard, P. (2003) Photosynthetic and Growth Responses of Three Freshwater Algae to Phosphorus Limitation and Daylength. Freshwater Biology, 48, 2141-2148. https://doi.org/10.1046/j.1365-2427.2003.01157.x

[13] Kardinaal, W.E.A., Janse, I., Kamst-Van Agterveld, M., Meima, M., Snoek, J., Mur, L.R., Huisman, J., Zwart, G. and Visser, P.M. (2007) Microcystis Genotype Succession in Relation to Microcystin Concentrations in Freshwater Lakes. Aquatic Microbial Ecology, 48, 1-12. https://doi.org/10.3354/ame048001

[14] Verspagen, J.M.H., Van de Waal, D.B., Finke, J.F., Visser, P.M., Donk, E.V. and Huisman, J. (2014) Rising $\mathrm{CO}_{2}$ Level Will Intensify Phytoplankton Blooms in Euthrophic and Hypertrophic Lakes. PLOS ONE, 9, e104325. https://doi.org/10.1371/journal.pone.0104325

[15] Pimentel, J.S.M. and Giani, A. (2014) Microcystin Production and Regulation under Nutrient Stress Conditions in Toxic Microcystis Strain. Applied and Environmental Microbiology, 80, 5836-5843.

[16] Bogorad, L. (1975) Phycobiliproteins and Complementary Chromatic Adaptation. 
Annual Review of Plant Physiology, 26, 369-401. https://doi.org/10.1146/annurev.pp.26.060175.002101

[17] Vincent, W.F. (2002) Cyanobacterial Dominance in the Polar Regions. In: Whitton B.A. and Potts, M., Eds., the Ecology of Cyanobacteria, Springer, Dordrecht, 321-340. https://doi.org/10.1007/0-306-46855-7 12

[18] Samsonoff, W. and MacColl, R. (2001) Biliproteins and Phycobilisomes from Cyanobacteria and Red Algae at the Extremes of Habitat. Archives of Microbiology, 176, 400-405. https://doi.org/10.1007/s002030100346

[19] Sivonen, K. and Jones, G. (1999) Cyanobacterial Toxins. In: Chorus, I. and Bartram, J., Eds., Toxic Cyanobacteria in Water. A Guide to Their Public Health Consequences, Monitoring and Management, St Edmundsbury Press, London, 41-111.

[20] Parker, D.L., Rai, L.C., Mallick, N., Rai, P.K. and Kumar, H.D. (1998) Effects of Cellular Metabolism and Viability on Metal Ion Accumulation by Cultured Biomass from a Bloom of the Cyanobacterium Microcystis aeruginosa. Applied and Environmental Microbiology, 64, 1545-1547.

[21] Oginni, G.F., Oloketuyi, S.F., Mazzega, E., Budasheva, H., Beran, A., Cabrini, M., Korte, D., Mladen, F. and De Marco, A. (2021) Nanobody-Dependent Detection of Microcystis aeruginosa by ELISA and Thermal Lens Spectrometry. Applied Biochemistry and Biotechnology, 193, 2729-2741. https://doi.org/10.1007/s12010-021-03552-6

[22] Yang, Z. and Kong, F. (2015) UV-B Exposure Affects the Biosynthesis Microcystin in Toxic Microcystis aeruginosa Cells and Its Degradation in the Extracellular Space. Toxins, 7, 4238-4252. https://doi.org/10.3390/toxins7104238

[23] Islam, M.A. and John, B. (2017) Growth and Photosynthetic Characteristics of Toxic and Non-Toxic Strains of the Cyanobacteria Microcystis aeruginosa and Anabaena circinalis in Relation to Light. Microrganisms, 5, Article No. 45. https://doi.org/10.3390/microorganisms5030045

[24] Kim, T.K. (2017) Understanding One-Way ANOVA Using Conceptual Figures. Korean Journal of Anesthesiology, 70, 22-26. https://doi.org/10.4097/kjae.2017.70.1.22

[25] Ranganathan, P., Pramesh, C.S. and Buyse, M. (2015) Common Pitfalls in Statistical Analysis: Clinical versus Statistical Significance. Perspectives in Clinical Research, 6, 169-170. https://doi.org/10.4103/2229-3485.159943

[26] Mishra, P., Singh, U., Pandey, C.M., Mishra, P. and Pandey, G. (2019) Alication of Student's $t$-Test, Analysis of Variance, and Covariance. Annals of Cardiac Anaesthesia, 22, 407-411. https://doi.org/10.4103/aca.ACA 9419

[27] Venugopal, V., Prasanna, R., Sood, A., Jaiswal, P. and Kaushik, B.D. (2006) Stimulation of Pigment Accumulation in Anabaena azollae Strains: Effect of Light Intensity and Sugars. Folia Microbiologica, 51, 50-56. https://doi.org/10.1007/BF02931450

[28] Romo, S. (1994) Growth Parameters of Pseudanabaena galeata Böcher in Culture under Different Light and Temperature Conditions. Algological Studies/Archiv für Hydrobiologie, 75, 239-248. https://doi.org/10.1127/algol stud/75/1995/239 